\title{
E1 SIGNAL PR0CESSING OF THE GALILEO SYSTEM IN THE NAVIGATION RECEIVER
}

\author{
Lucjan Setlak, Rafał Kowalik
}

Department of Avionics and Control Systems, Faculty of Aviation Division, Military University of Aviation, Deblin, Poland

*E-mail of corresponding author: r.kowalik@law.mil.pl

\section{Resume}

The subject of this article are issues related to the navigation system in the field of analyzing the processed signal in the GNSS system receiver. The main purpose of the work is to discuss the Galileo E1 signal processing methods in the GNSS navigation system receiver, supported by adapted research tools in terms of solving the research problem (analysis, model, simulation tests) and the mathematical apparatus used. Key studies are concentrated around the process of generating the navigation data, dispersing sequences and signal modulation. Thus, when designing a receiver, it is better to use the simulation signals than the real ones, since one can get more control over the properties of the received signal. In the final part of the work, in accordance with the subject of research, based on the developed appropriate research tools, observations and final conclusions were formulated, which have practical applications.

\section{Article info}

Received 8 October 2020

Accepted 24 November 2020

Online 26 May 2021

\section{Keywords:}

signal processing,

E1 signal,

Galileo system, navigation system receiver
ISSN 1335-4205 (print version) ISSN 2585-7878 (online version)

\section{Introduction}

In recent years, many efforts have been made to design and implement the Galileo signal simulator. This work presents simulations of the GNSS/Galileo navigation system transmitter signals via a graphical programming language, which is the Matlab/Simulink programming environment, with the same efficiency as text programming languages.

The GUI (Graphical User Interface) environment was used. In addition, use of a graphical programming language makes every part of the navigation system transmitter architecture very clear and much easier to understand and modify. The Galileo system receiver consists of four main components: acquisition, satellite tracking, digital processing and positioning efficiency. It is based entirely on the algorithms of the Matlab/ Simulink program [1-2].

In addition, some of the decoding algorithms were previously developed for the GPS system technology, so everything had to be adjusted, including the navigation message. However, it should be noted that majority of the Galileo system algorithms have been recently developed.

Real Galileo signals taken from the GNSS navigation system receiver were used for the tests. These signals were helpful, among others in understanding the structure of navigational messages and obtaining parameters transmitted by the Galileo system signals.
However, it should be mentioned that study encountered some inconvenience due to insufficient information on the system under consideration. Although there is a lot of information and publications in the field of the GPS, the Galileo system is still under development and some specifications have not been fully defined or have been left to ongoing improvement.

In the rest of this article, in accordance with the subject of the study, the issue of the positioning efficiency of the GNSS navigation system (Galileo) was considered from an aspect of an ideal and not ideal mathematical model of the pseudo-distance of the system [3-5].

\section{Positioning performance}

Navigation data consists of 4 types of data needed to perform positioning, i.e. ephemeris parameters necessary to indicate the position of the satellite relative to the receiver, time and clock correction parameters to calculate the pseudorange, service parameters for identifying satellites and signal quality and almanac parameters, indicating the positions of other satellites. After presenting the ephemeris, services and almanac parameters, it is time to delve into time parameters and clock correction. This is necessary to calculate the so-called pseudorange. Then the equations used to find the position of the satellite would be presented. 


\subsection{Pseudorange of the ideal model}

The relative pseudorange is the distance (or time) between the two reference points. There is no absolute reference to time in the GNSS system. The only reference to time is the sampling frequency and the clock deviation of the receiver [6-8].

To determine its position, the receiver determines the distances from at least four satellites, as well as their positions at the time of broadcasting. Knowing the orbital parameters of the satellites, these positions can be calculated for any point in time. The pseudorange of each satellite is obtained by multiplying the speed of light by the time the signal traveled from the satellite to the receiver [9-11]. The ideal case for calculating the pseudorange is when there are no errors with the transmitter and receiver clock, ionosphere, troposphere or receiver noise. This case is calculated according to:

$$
\begin{aligned}
& R_{i}\left(t_{T}, t_{R}\right)=\left|r_{s i}\left(t_{T_{i}}\right)-r_{R}\left(t_{R}\right)\right|= \\
& =\sqrt{\left(x_{s i}-x_{R}\right)^{2}+\left(y_{s i}-y_{R}\right)^{2}+\left(z_{s i}-z_{R}\right)^{2}}
\end{aligned}
$$

where: $R_{i}\left(t_{T}, t_{R}\right)$ - the distance between the transmitter and the receiver, $t_{R}$ - the moment of time when the received signal arrives at the receiver, $t_{T_{i}}$ - the moment of time when the signal is sent by satellite $i$.

One can also define the delay associated with the satellite $i$, marked $\tau_{i}$ and written as:

$$
\begin{aligned}
& R_{i}\left(t_{T}, t_{R}\right)=\left|r_{s_{i}}\left(t_{T_{i}}\right)-r_{R}\left(t_{R}\right)\right| \tau_{i}= \\
& =\frac{R_{i}\left(t_{T}, t_{R}\right)}{c}=t_{R}-t_{T_{i}} .
\end{aligned}
$$

At least 3 satellites are required to calculate position. A non-linear system of three equations with three unknowns must be solved.

\subsection{Pseudorange of the non-ideal model}

This is the real case where errors occur. The transmission time of the satellite $i$ is:

$t_{T_{i}}=t_{T_{i}}^{\text {Galileo }}+\Delta t_{T_{i}}$

where: $\Delta t_{T_{i}}$ - satellite clock error.

The signals reach the receiver at the following moment, it can be written as:

$t_{R}^{\text {Galileo }}=t_{T_{i}}^{\text {Galileo }}+\tau_{i}-\Delta t_{1}^{\text {rel }}$,

where: $\Delta t_{i}^{\text {rel }}$ - relativistic correction.

However, the moment measured by the receiver, taking into account the above Equation (4), can be presented in the following form:

$$
\begin{aligned}
& t_{R}=t_{R}^{\text {Galileo }}+\Delta t_{R}+\Delta t_{n}=t_{T_{i}}^{\text {Galileo }}+\tau_{i}-\Delta t_{i}^{\text {rel }}+ \\
& +\Delta t_{R}+\Delta t_{n},
\end{aligned}
$$

where: $\Delta t_{R}$ - receiver clock error, $\Delta t_{n}$ - delay caused by the receiver measurement error due to the white noise. In contrast, the random variable has the same statistical properties for each satellite. Finally, taking into account Equation (3), the following form was obtained [12-14]:

$t_{R}=t_{T_{i}}+\tau_{i}-\left(\Delta t_{T_{i}}+\Delta t_{i}^{r e l}\right)+\Delta t_{R}+\Delta t_{n}$.

It should be noted that $\Delta t_{R}$ is common to all satellites. The delay $\tau_{i}$ is obtained by the sum of the geometric $\tau_{i}^{\text {geo }}$, ionospheric $\Delta t_{i}^{i o n}$ and tropospheric $\Delta t_{i}^{\text {trop }}$ delays, as shown in the following form:

$\tau_{i}=\tau_{i}^{g e o}+\Delta t_{i}^{i o n}+t_{i}^{\text {trop }}$.

The total delay between transmitter and receiver is:

$\tau_{i}^{\text {tot }}=t_{R_{i}}-t_{T_{i}}=\tau_{i}-\left(\Delta t_{T_{i}}+\Delta t_{i}^{r e l}\right)+\Delta t_{R}+\Delta t_{n}$.

Replacing $\tau_{i}$ by Equation (7), the following form was obtained:

$\tau_{i}^{\text {tot }}=\tau_{i}^{g e o}+\Delta t_{i}^{i o n}+\Delta t_{i}^{\text {trop }}-\left(\Delta t_{T_{i}}+\Delta t_{i}^{\text {rel }}\right)+$
$+\Delta t_{R}+\Delta t_{n}$

After calculating the total delay, it is possible to obtain a pseudorange by multiplying it by the speed of light $c$, resulting in [15-17]:

$\rho_{i}=c \tau_{i}^{\text {tot }}=R_{i}+c \Delta t_{i}^{i o n}+c \Delta t_{i}^{\text {trop }}-$
$-c\left(\Delta t_{T_{i}}+\Delta t_{i}^{r e l}\right)+c \Delta t_{R}+c \Delta t_{n}$.

where: $R_{i}$ - the geometric distance and as already shown in Equation (1) of the ideal model, the geometric distance is calculated as follows:

$$
\begin{aligned}
& R_{i}=R_{i}\left(t_{T_{i}}^{\text {Galileo }}, t_{R}^{\text {Galileo }}\right)=\left|r_{s i}\left(t_{T_{i}}^{\text {Galileo }}\right)-r_{R}\left(t_{R}^{\text {Galileo }}\right)\right|, \\
& R_{i}\left(t_{T_{i}}^{\text {Gal }}, t_{R}^{\text {Gal }}\right)=\sqrt{\begin{array}{l}
{\left[x_{s i}\left(t_{T_{i}}^{\text {Gal }}\right)-x_{r}\left(t_{R}^{\text {Gal }}\right)\right]^{2}+} \\
+\left[y_{s i}\left(t_{T_{i}}^{\text {Gal }}\right)-y_{r}\left(t_{R}^{\text {Gal }}\right)\right]^{2}+ \\
+\left[z_{s i}\left(t_{T_{i}}^{\text {Gal }}\right)-z_{r}\left(t_{R}^{\text {Gal }}\right)\right]^{2}
\end{array}}
\end{aligned}
$$

It should be noted that both the parameter $\Delta t_{R}$ from Equation (10) and the parameter $r_{R}$ from Equation (11) do not depend on the position of the satellites. The parameter $\Delta t_{R}$, i.e. the receiver clock error, is not known, so it can be treated as another unknown. Hence, four satellites are necessary to determine coordinates of the receiver and its clock error.

\section{Linearization}

To solve the obtained system of equations, it should be taken into account that it is non-linear. It should be linearized, assuming that the approximate position and 


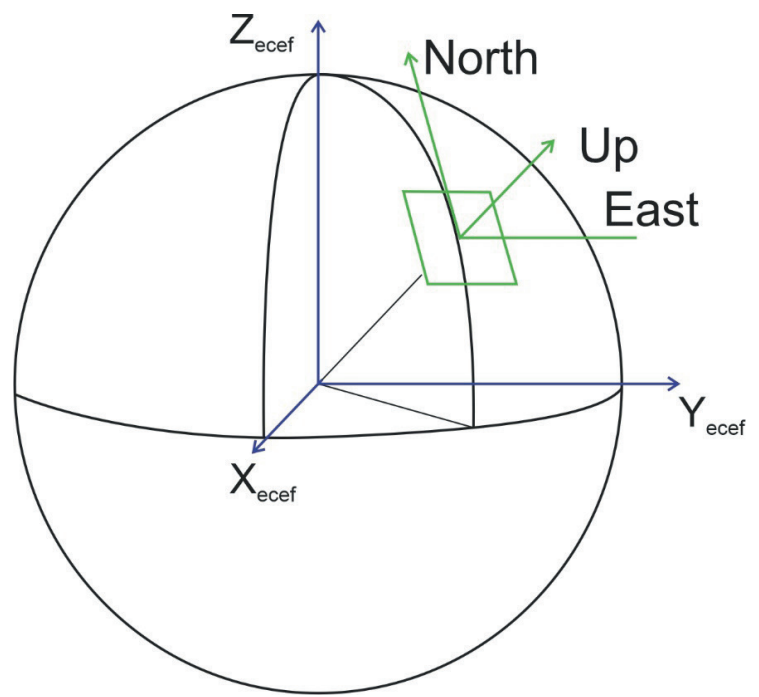

Figure 1 Coordinate system used in the mathematical description

approximate clock error are known. The pseudorange is derived from the following formula [18-20]:

$\delta \rho_{i}=\frac{\delta \rho_{i}}{\delta x_{R}} \delta x_{R}+\frac{\delta \rho_{i}}{\delta y_{R}} \delta y_{R}+\frac{\delta \rho_{i}}{\delta z_{R}} \delta z_{R}+\frac{\delta \rho_{i}}{\delta w_{R}} \delta w_{R},(13)$

where: $w_{R}=c \Delta t_{R}$.

In turn, partial derivatives can be written in the following forms:

$\frac{\delta \rho_{i}}{\delta x_{R}}=\frac{-x_{S i}-x_{R}}{R_{i}}$,

$\frac{\delta \rho_{i}}{\delta y_{R}}=\frac{-y_{S_{i}}-y_{R}}{R_{i}}$,

$\frac{\delta \rho_{i}}{\delta z_{R}}=\frac{-z_{S_{i}}-z_{R}}{R_{i}}$,

$\frac{\delta \rho_{i}}{\delta w_{R}}=1$

Then it is defined as:

$\delta_{p}=\left[\delta x_{R} \delta y_{R} \delta z_{R} \delta w_{R}\right]^{T} ; \delta_{p}=\left[\delta \rho_{1} \delta \rho_{2} . . \delta \rho_{K}\right]^{T}$,

$A=\left(\begin{array}{cccc}a_{11} & a_{12} & a_{13} & 1 \\ a_{21} & a_{22} & a_{23} & 1 \\ . . & . . & . . & 1 \\ a_{K 1} & a_{K 2} & a_{K 3} & 1\end{array}\right)$,

where:

$a_{i 1}=\frac{-x_{s i}-x_{R}}{R_{i}}, a_{i 2}=\frac{-y_{s i}-y_{R}}{R_{i}}, a_{i 3}=\frac{-z_{s i}-z_{R}}{R_{i}}$ and $p=\left[x_{R} y_{R} z_{R} w_{R}\right]^{T}$ - specifies the extended vector with receiver error.

It can therefore be written in the following form:

$\delta \rho=A \delta p$

The position of the receiver can be calculated iteratively. Regardless of whether an approximate extended position vector is available at the moment, the estimation can be improved as follows:

$p^{(k)}=p^{(k-1)}+\delta p^{(k)}$

where: $\delta p^{(k)}$ - solution of the linear system.

However, due to the fact that it is possible to use more equations than unknown quantities, the solution will be the so-called the least squares method [21-23]:

$\delta p^{(k)}=\left(A^{(k-1) T} A^{(k-1)}\right)^{-1} A^{(k-1) T} \delta \rho^{(k-1)}$,

where: $\delta \rho^{(k)}=\hat{\rho}-\rho^{k}$.

This process will continue until the condition is met $\delta p<10^{-12}$.

\subsection{Calculation of the satellite position}

To obtain the position of the satellite in the Earthrelated coordinate system ECEF (Earth-Centered Earth-Fixed), the issues considered in this section use all information obtained from ephemeris data.

The calculated average movement $n_{0}$, is the average angular velocity of the satellite:

$n_{0}=\frac{2 \pi}{T}=\sqrt{\frac{\mu}{A^{s}}}$,

where: $\mu$ - geocentric gravitational constant, $A$ - semimajor -axis.

After obtaining the average movement in $\left[\frac{\mathrm{rad}}{\mathrm{s}}\right]$, the corrected average movement can be calculated [24-26]:

$n=n_{0}+\Delta n$

where: $\Delta n$ - average movement difference from the calculated value.

The actual total time difference between time $t$ and epoch $t_{0_{s}}$ is $t_{k}$, which can be determined by the following: 
$t_{k}=t-t_{0_{s}}$,

where: $t$ - is the Galileo system time.

The average anomaly can be determined from the following:

$M=M_{0}+n t_{k}$,

where: $M_{0}$ - mean anomaly at reference time.

The Kepler equation for the eccentric $E$ anomaly (can be solved by iteration) is defined as:

$M=E-e \sin (E)$,

where: $e$ - eccentricity.

The condition of relativistic correction can be obtained by:

$\Delta t_{r}=F e A^{\frac{1}{2}} \sin (E)$,

where: $F=-2 \mu^{\frac{1}{2}} / c^{2}$ - constant.

The satellite time correction (in seconds) is modeled by the following second order polynomial that defines parabola according to the following equation [27-29]:

$$
\begin{aligned}
& \Delta t_{S V}(X)=a_{f 0}+a_{f 1}(X)\left[t-t_{0 C}(X)\right]+ \\
& +a_{f 2}(X)\left[t-t_{0 C}(X)\right]^{2}+\Delta t_{r},
\end{aligned}
$$

where: $a_{f 0}, a_{f 1}, a_{f 2}$ - SV (Space Vehicle) clock correction coefficients, $t_{0 C}$ - clock correction related to Time of Week, $(X)=\left(f_{1}, f_{2}\right)$ - frequency combination $f_{1}$ and $f_{1}$ used in the clock model.

The true anomaly is defined as:

$$
\begin{aligned}
& v=\tan ^{-1}\left\{\frac{\sin (v)}{\cos (v)}\right\}=\tan ^{-1} \times \\
& \times\left\{\frac{\sqrt{1-e^{2}} \sin (E) /(1-e \cos (E))}{(\cos (E)-e) /(1-e \cos (E))}\right\} .
\end{aligned}
$$

The argument of latitude can be determined from the formula:

$u=v+\omega$

The argument of latitude correction is calculated as follows:

$$
\delta u=C_{u s} \sin (2 \Phi)+C_{u c} \cos (2 \Phi) .
$$

The radius vector correction is determined from the following formula:

$\delta r=C_{r s} \sin (2 \Phi)+C_{r c} \cos (2 \Phi)$.

However, the inclination correction is determined from the following equation:

$\delta i=C_{i s} \sin (2 \Phi)+C_{i c} \cos (2 \Phi)$.
The anomaly at epoch $t$ is the sum of the argument of latitude and its correction:

$u=\Phi+\delta u$.

The corrected radius vector is calculated from the formula:

$r=A(1-e \cos (E))+\delta r$.

In contrast, improved inclination is:

$i=i_{0}+\delta i+\left(\dot{\bullet}_{i}\right) t_{k}$.

Then the position in the orbital plane can calculated as follows:

$x^{\prime}=r \cos u, y^{\prime}=r \sin u$.

The right-ascension of the ascending node $\Omega$ is calculated as follows according to equation [30-32]:

$\Omega=\Omega_{0}+\left(\begin{array}{c}\bullet \\ \Omega\end{array}\right) t_{k}$

However, this result is obtained for the geocentric inertial coordinate system ECIS (Earth-Centered Inertial System). After receiving $\Omega$, the next step to get the result in the ECEF system is:

$\Omega=\Omega-\omega_{E} t_{k}-\omega_{E} t_{0_{s}}$,

where: $\omega_{E}$ - average angular velocity of the Earth.

Finally, to find the satellite position, the following form was obtained:

$\left(\begin{array}{l}x \\ y \\ z\end{array}\right)=\left(\begin{array}{c}x^{\prime} \cos (\Omega)-y^{\prime} \sin (\Omega) \cos (i) \\ x^{\prime} \sin (\Omega)+y^{\prime} \cos (\Omega) \cos (i) \\ y^{\prime} \sin (i)\end{array}\right)$.

\subsection{BOC modulation}

The Galileo system signals are modulated using a new technique called BOC (Binary Offset Carrier) modulation. The BOC modulation was designed to modernize the GPS and Galileo systems to facilitate addition of other signals that have the same carrier frequency in the radio frequency bands, without interfering with other signals.

Advantages of the BOC modulation are: improvement of traditional GNSS system signal properties for better resistance to multi-path and interference with various types of noise and ensuring the spectral isolation between signals with the same carrier frequency.

The BOC modulated signal consists of a sinusoidal carrier, a rectangular subcarrier (BOCsin and $B O C \cos )$, a pseudo-random PRN code (Pseudorandom Noise) and a data sequence. The signal is presented as BOC 


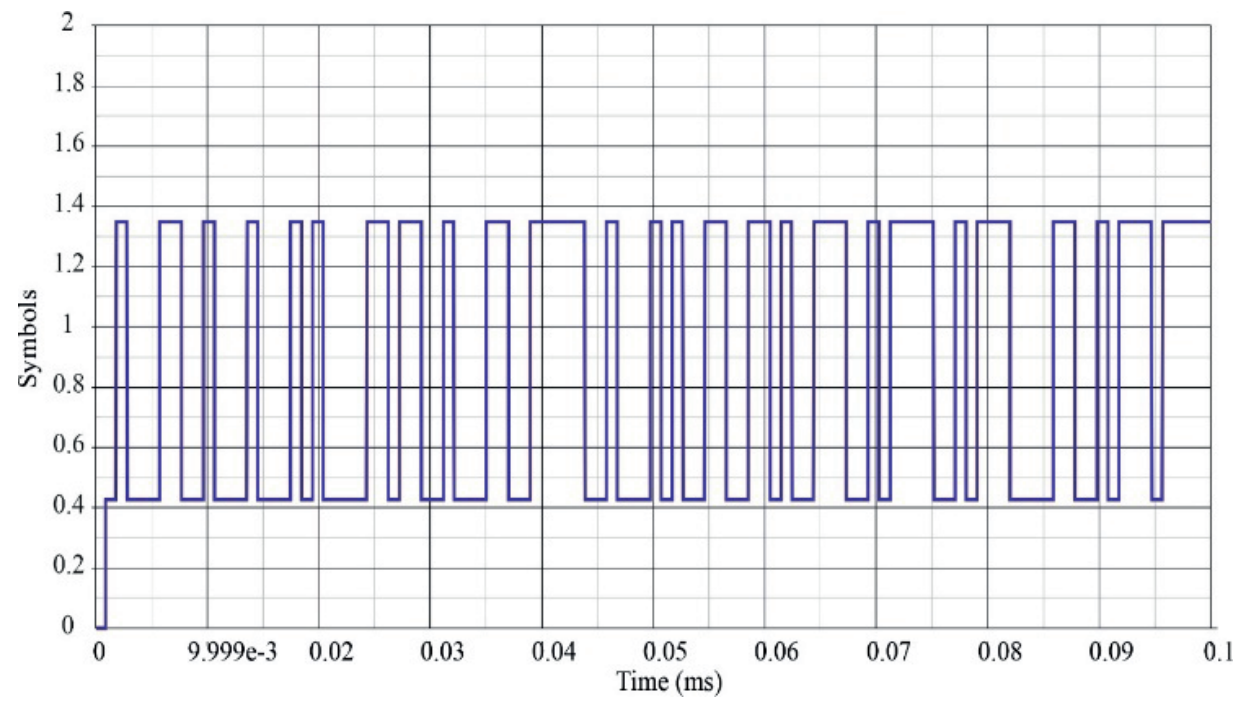

Figure 2 CBOC subcarrier of B channel with $B O C$ (1.1) and $B O C$ (6.1)

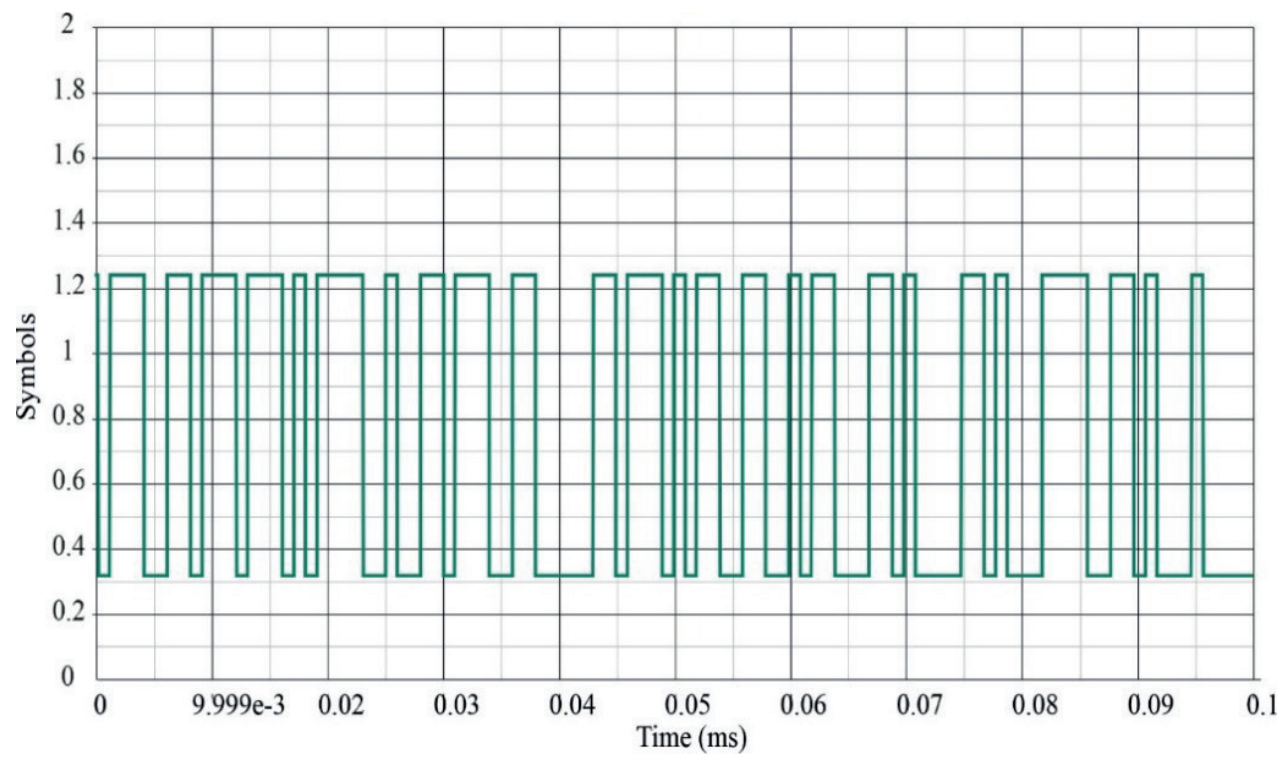

Figure 3 CBOC subcarrier of $C$ channel with $B O C$ (1.1) and BOC (6.1)

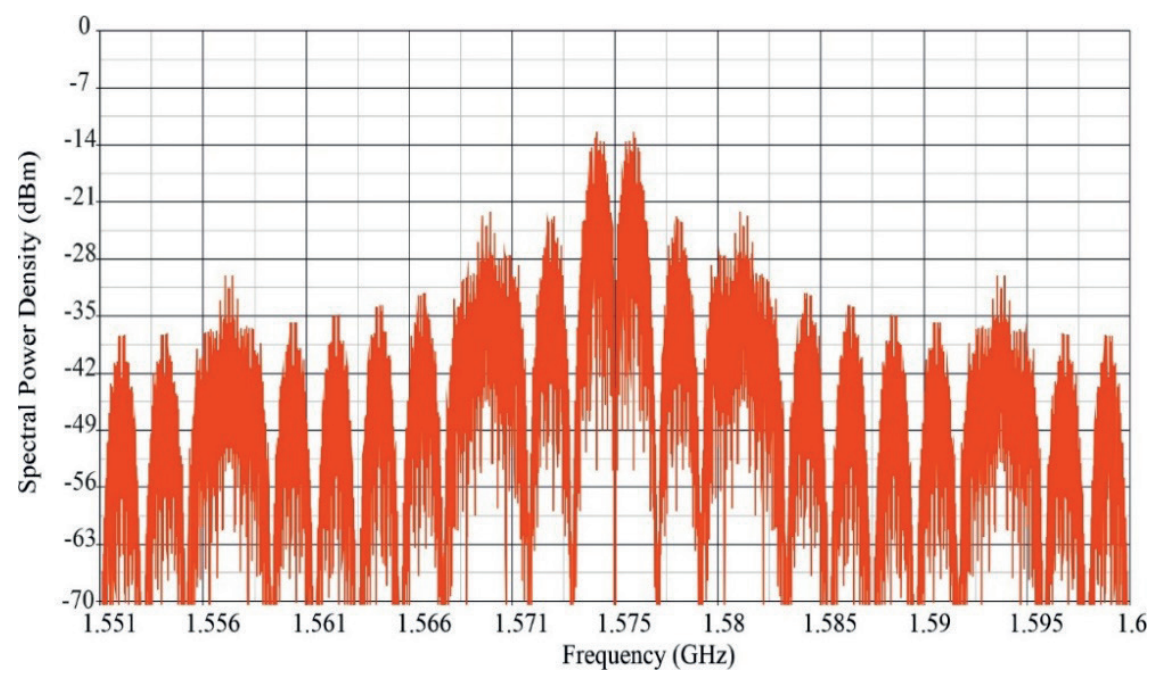

Figure 4 Spectral power density of E1 signal for the CBOC modulation (1.6) 


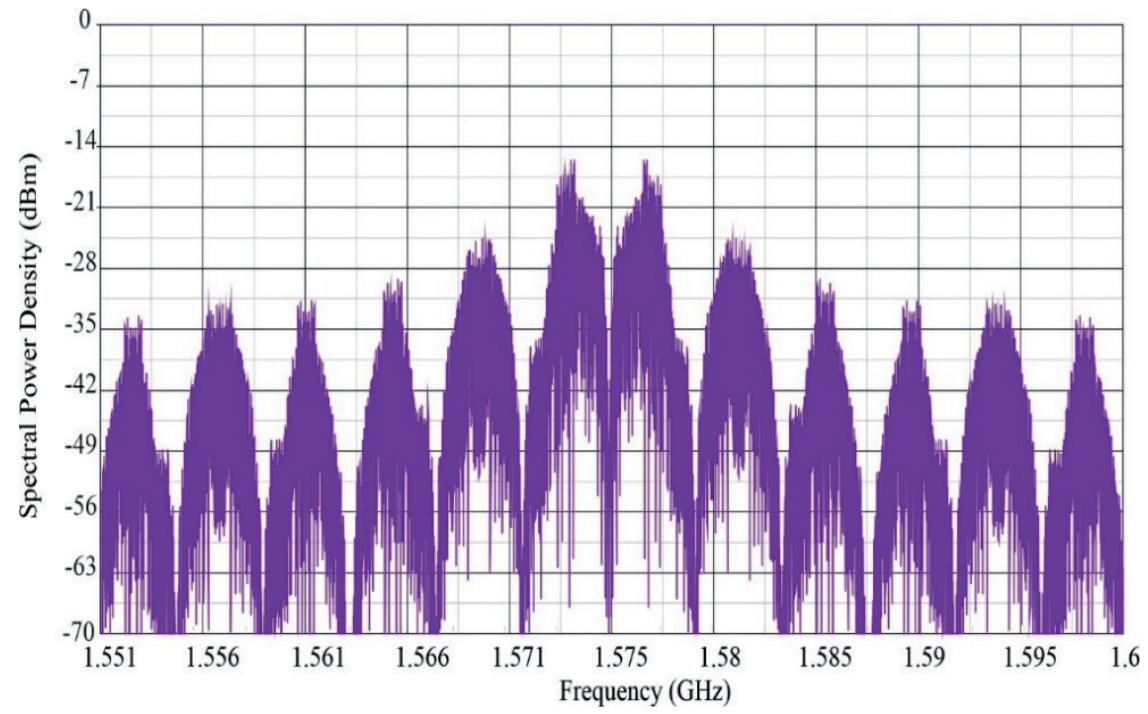

Figure 5 Spectral power density of E1 signal for the CBOC modulation (6.2)

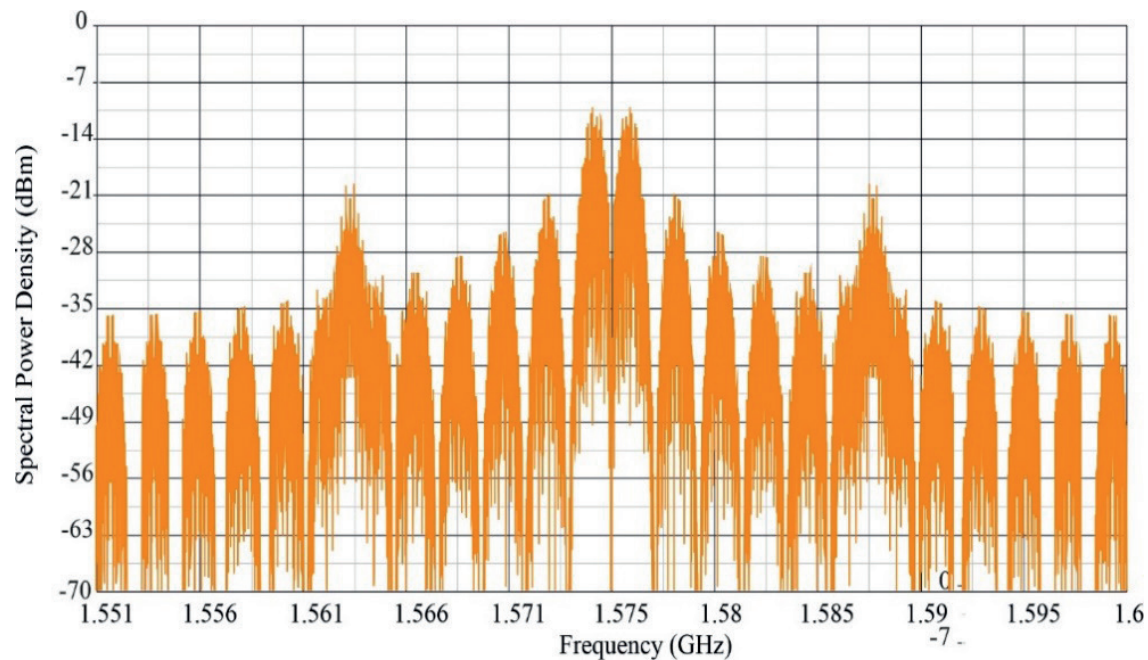

Figure 6 Spectral power density of E1 signal for the CBOC modulation (12.1)

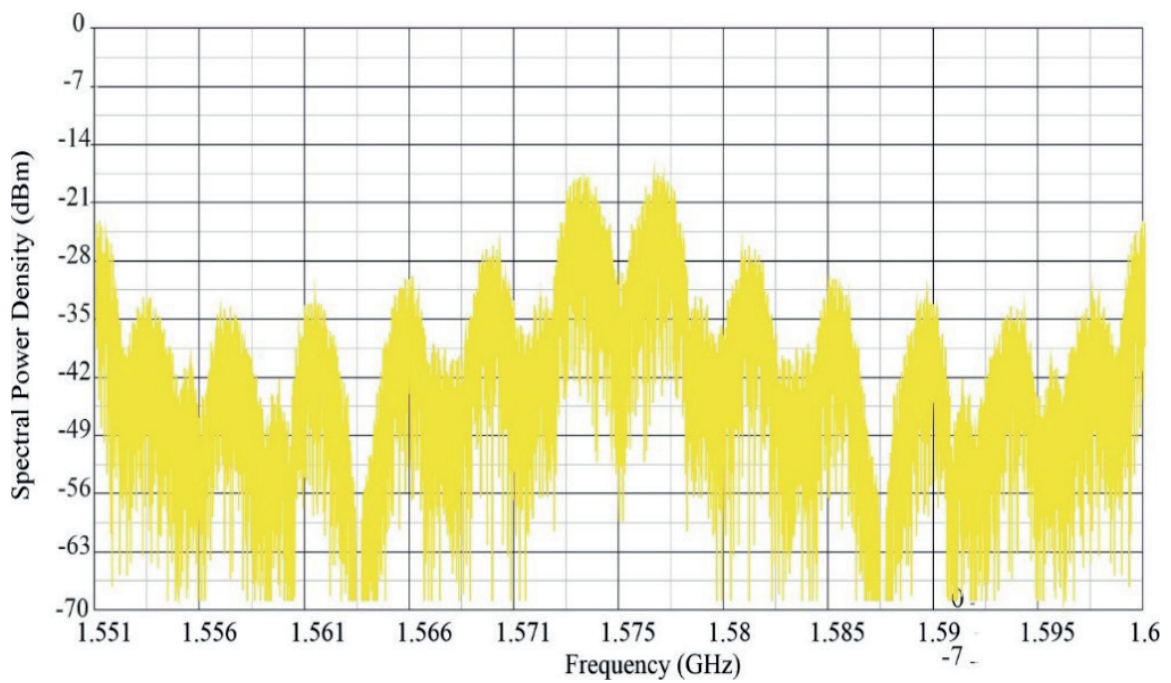

Figure 7 Spectral power density of E1 signal for the CBOC modulation (2.20) 


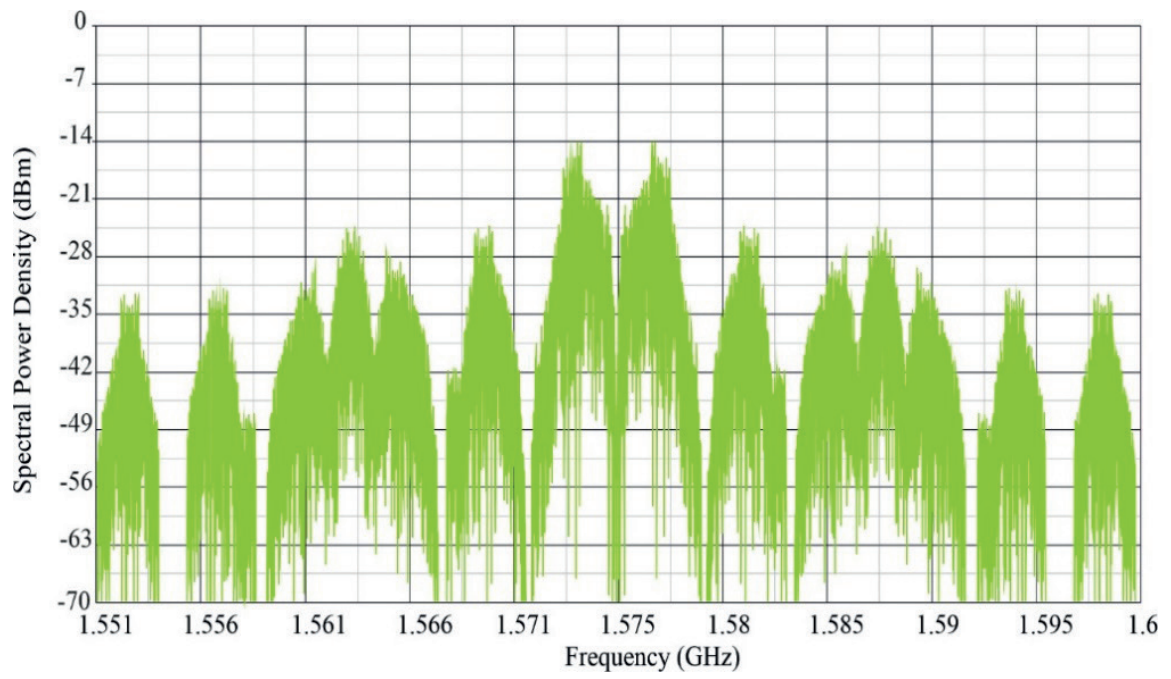

Figure 8 Spectral power density of E1 signal for the CBOC modulation (2.12)

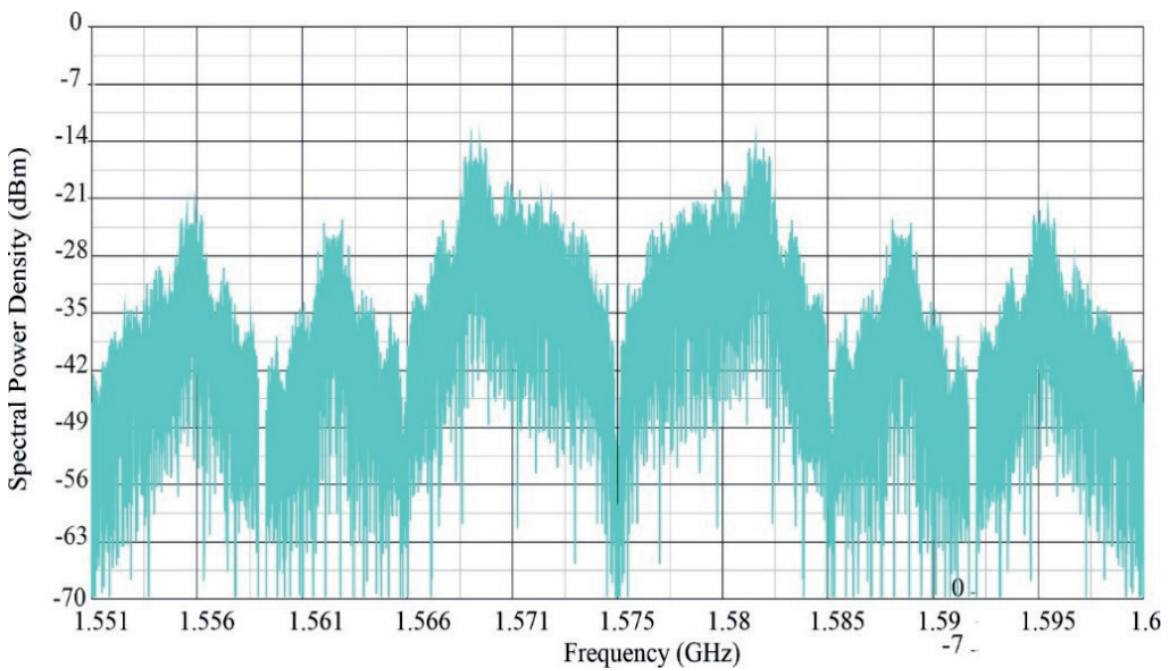

Figure 9 Spectral power density of E1 signal for the CBOC modulation (6.12)

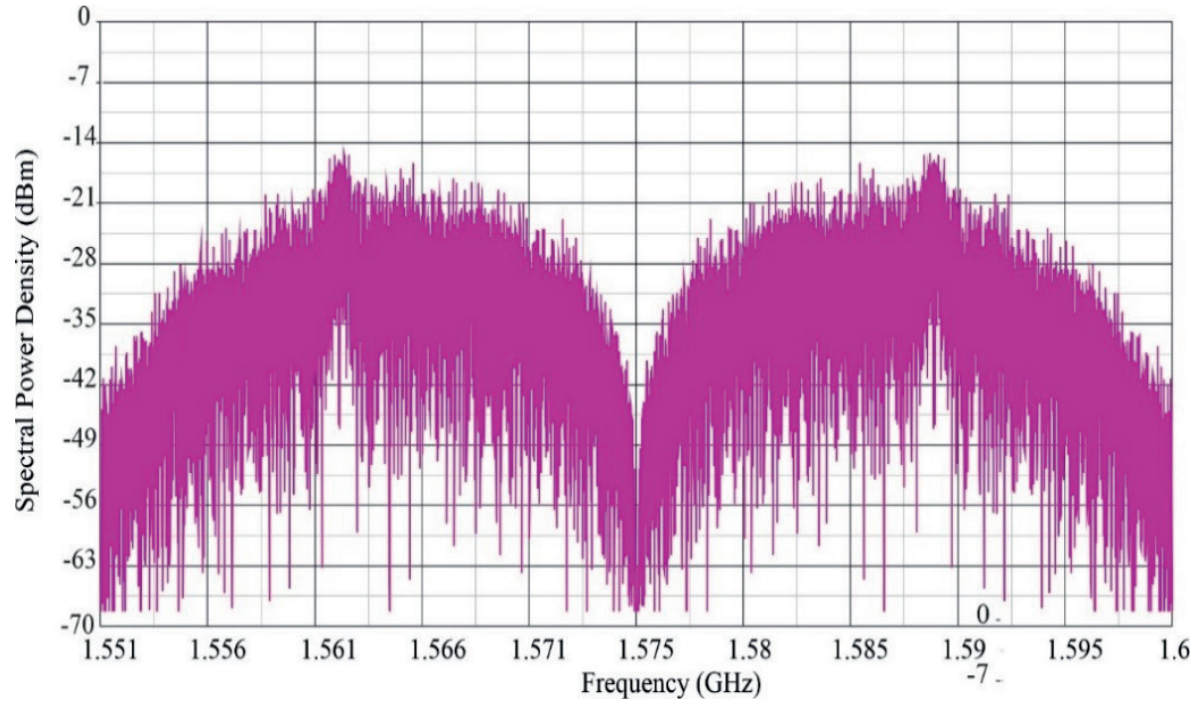

Figure 10 Spectral power density of E1 signal for the CBOC modulation (12.12) 
$(m, n)$. Two independent parameters $m$ and $n$ are used to concentrate the signal strength in specific parts of the spectrum to reduce interference with other signals [33-34].

Parameters $m$ and $n$ are defined as follows:

$$
m=\frac{F_{s}}{F_{0}}, n=\frac{F_{c}}{F_{0}}
$$

where: $F_{s}$ - defines the subcarrier frequency in $[\mathrm{MHz}]$, $F_{c}$ - means transmission speed in [Mcps], $F_{0}$ - reference frequency $F_{0}=1.023[\mathrm{MHz}]$ which is generated by the atomic clock on satellites.

\section{Selected tests for the BOC modulation}

Channels $B$ and $C$ are modulated by "Composite BOC" modulation (CBOC $(6.1,1 / 11))$. CBOC modulation combines BOC (1.1) and BOC (6.1).

The CBOC modulation results from the multiplexing of the narrowband BOC signal (1.1), whose subcarrier frequency is $1.023[\mathrm{MHz}]$ and the transmission speed 1.023 [Mcps], with the wideband BOC signal (6.1), with the subcarrier frequency $6.138[\mathrm{MHz}]$ and the transmission speed 1.023 [Mcps].

The normalized CBOC power spectral density (6.1, $1 / 11)$ is obtained according to equation:

$$
\begin{aligned}
& G_{C B O C}\left(6.1 \frac{1}{11}\right)(f)=\frac{10}{11} G_{B O C}(1.1)+ \\
& +G_{B O C}(6.1)(f),
\end{aligned}
$$

where: $G_{C B O C(m, n)}(f)$ - PSD (Packet-Switched Data) unit of BOC sinusoidal modulation.

Thus 1/11 of the power is allocated on the high frequency channel (BOC (6.1)). CBOC modulation for $\mathrm{B}$ and $\mathrm{C}$ channels can be illustrated by the following equations:

$$
\begin{aligned}
& s c B(t)=\alpha s c(t)_{B O C(1.1)}+\beta s c(t)_{B O C(6.1)}, \\
& s c C(t)=\alpha s c(t)_{B O C(1.1)}+\beta s c(t)_{B O C(6.1)}, \\
& \text { where: } \alpha=\sqrt{\frac{1}{10}} \text { and } \beta=\sqrt{\frac{10}{11}} .
\end{aligned}
$$

Figures 2 and 3 show the generated $\mathrm{CBOC}$ subcarriers for $s c B(t)$ and $s c C(t)$ using the Matlab/ Simulink environment.

Equations (46) and (47) identify BOCsin and BOCcos respectively:

$$
\begin{aligned}
& B O C \sin : s c(t)=\operatorname{sign}(\sin (2 \pi F s t)), \\
& B O C \cos : s c(t)=\operatorname{sign}(\cos (2 \pi F s t)),
\end{aligned}
$$

where: $F_{s}$ - subcarrier frequency.

It should be noted that the BOC modulation divides the spectrum into two main symmetrical layers focused on $\pm f_{s}[\mathrm{MHz}]$ (subcarrier frequency) around the carrier frequency. The generated PSD from the SE1 signal is shown in Figures 4-10.

Figures 4-10, illustrate the signal spectra modulated by the composite CBOC method $(n, m)$, differing in the occurrence of the main leaves representing the main band in which the transmission of the Galileo system radio signals is carried out and the shift, causing the use of additional band for other signal transmissions or services.

The above process is possible both by changing the transmission speed of the carrier wave $n$ and the transmission speed of $m$ chips. Based on the analysis of the spectra of the signal modulated on individual waveforms, it can be observed how the process of extending, adding a new band or its shift takes place for different values of $n$ and $m$.

Especially valuable in this context is the signal power spectral density analysis E1 for the CBOC modulation (6.12) as shown in Figure 9, considering a candidate/pretender signal providing a wide frequency band $\mathrm{E} 5 \mathrm{a} / \mathrm{E} 5 \mathrm{~b}$ for the transmission of Galileo navigation signals.

It should be noted that the CBOC (6.12) signal is very interesting from the point of practical use because it provides spectral isolation between the two upper and lower bands of the same navigation signal. In this way it is possible to track each element separately or together.

\section{Conclusions}

The Power Spectral Density (PSD) for different types of BOC signal is shown. The analysis was carried out in this aspect comparing the BOC and $\mathrm{CBOC}$ modulations and then the method of generating the BOC signals was considered. In addition, the necessary tests and simulations of the process of generating CBOC (1.3), CBOC (12.1), CBOC (6.12) and CBOC (12.12) signals modulated with both sine and cosine subcarriers were performed using the Matlab/Simulink programming environment. The simulation tests were successful. Signal waveforms have been generated for channel $B$ navigation data, $B$ and $C$ channel dispersing sequences and modulated $B$ and $C$ subcarrier channels.

The rectangular waveform of channel $C$ dispersing sequence with primary and secondary code has a longer period than the dispersing sequence of channel $B$ with only the basic code. The waveforms of modulated $B$ and $C$ subcarrier channels are essentially no different (Figures 1-2).

In general, graphical programming languages facilitate system design since they clearly define the relationship between the system modeling, simulation system and system implementation [35-36]. Since the Galileo system is still being developed and its improvements are expected, the $E 1$ signal simulation shown in this work may contribute to facilitating the redesign of the transmitter and receiver. 
In addition, the simulation model may have educational purposes due to the transparency of the design and algorithm simulation. The introduced model may also facilitate system implementation. Implementation tools available in the Matlab/Simulink module, such as „Code Composer Studio”, can be used at the implementation stage.

On the other hand, since the transmitter design of most GNSS systems is similar, the simulation models introduced in this work can be used in design of the transmitter simulator, which will have a direct positive impact on the testing stages and checking the receiver.

\section{References}

[1] BONE, K., AKOS, D. A Software-defined GPS and Galileo receiver; a single-frequency approach. New York: Birkhauser. 2007. ISBN 978-0-8176-4390-4.

[2] GODET, J. Technical annex to Galileo SRD signal plans. STF annex SRD 2001/2003. Draft 1. July 2003.

[3] European Union. European GNSS (Galileo) open service signal. In: Space interface document. OS SIS ICD, Vol. 3, Issue 1, 2016.

[4] DE GAUDENZI, R., HOULT, N., BATCHELOR, A., BURDEN, G., QUINLAN, M. Galileo signal validation development. John Wiley \& Sons, Ltd., 2000.

[5] AVILA-RODRIGUEZ, J.-A., PANY, T., HEIN, G. W. Bounds on signal performance regarding multipathestimating discriminators. In: International Technical Meeting of the Institute of Navigation ION-GNSS 2006: proceedings. 2006.

[6] AVILA-RODRIGUEZ, J.-A., HEIN, G. W., WALLNER, S., SCHUELER, T., SCHUELER, E., IRSIGLER, M. Revised combined Galileo/GPS frequency and signal performance analysis. In: International Technical Meeting of the Institute of Navigation ION-GNSS 2005: proceedings. 2005.

[7] BAO-YEN TSUI, J. Fundamentals of Global Positioning System receivers: A software approach. 2. ed. John Wiley \& Sons, 2005. ISBN 0-471-38154-3.

[8] European Space Agency / European GNSS Supervisory Authority, Galileo Open Service - Signal in Space Interface Control Document. OS SIS ICD, Issue 1.1, September 2010.

[9] HEIN, G. W., AVILA-RODRIGUEZ, J. A., WALLNER, S. The Galileo code and others. Inside GNSS. 2006, p. 62-74. ISSN 2329-2970.

[10] GRZEGORZEWSKI, M. Results of a research predicting the position of an aircraft during approach and landing using the bessel function. Journal of Theoretical and Applied Mechanics [online]. 2013, 51(4), p. 915-926. ISSN 1429-2955.

[11] SETLAK, L., KOWALIK, R. Analysis, mathematical model and simulation tests of the unmanned aerial vehicle control system. ITM Web of Conferences [online]. 2019, 24, 01005. eISSN 2271-2097. Available from: https://doi.org/10.1051/itmconf/20192401005

[12] KAPLAN, E. D. Understanding GPS principles and applications. 1. Ed. Artech-House Publishers, 1996. ISBN 9780890067932.

[13] FERNANDEZ-PRADES, C., AVILES, C., ESTEVE, L., ARRIBAS, J., CLOSAS, P. An open source galileo E1 software receiver. In: 6th ESA workshop on Satellite Navigation Technologies and European GNSS Signals and Signal Processing NAVITEC: proceeding, ESTEC, 2012.

[14] AVILA-RODRIGUEZ, J.-A. On optimized signal waveforms for GNSS. Ph.D. thesis. Neubiberg, Germany: University FAF Munich, 2007.

[15] DE LATOUR, A. Code tracking performance of PRS and M-code signals. In: 1st CNES workshop on Galileo signals: proceedings. 2006.

[16] WALLNER, S., AVILA-RODRIGUEZ, J.-A., HEIN, G. W., RUSHANAN, J. J. Galileo E1 OS and GPS L1C pseudo random noise codes - requirements, generation, optimization and comparison. In: International Technical Meeting of the Institute of Navigation ION-GNSS 2006: proceedings. 2006.

[17] RIES, L., LESTARQUIT, L., ISSLER, J-L., PRATT, A. R., HEIN, G., GODET, J., DONDL, P., COUTURIER, F., ERHARD, P., OWEN, J. I. R., LUCAS-RODRIGUEZ, R., MARTIN, J.-C. New investigations on wide band GNSS2 signals. In: European Navigation Conference GNSS: proceedings. 2003.

[18] SETLAK, L., KOWALIK, R., SMOLAK, M. Doppler delay in navigation signals received by GNSS receivers. In: WSEAS Transactions on Applied and Theoretical Mechanics, 3rd International Conference on Applied Physics, System Science and Computers APSAC 2018: proceedings. 2018. Lecture Notes in Electrical Engineering. Vol. 574 , p. $3-8$.

[19] IRSIGLER, M., AVILA-RODRIGUEZ, J.-A., HEIN, G. W. Criteria for GNSS multipath performance assessment. In: 18th International Technical Meeting of the Satellite Division of the Institute of Navigation ION GNSS 2005: proceedings. 2005. 
[20] HEIN, G. W., GODET, J., ISSLER, J.-L., MARTIN, J.-C., LUCAS-RODRIGUEZ, R., PRATT, T. The Galileo frequency structure and signal design. In: International Technical Meeting of the Institute of Navigation IONGNSS 2001: proceedings. 2001.

[21] HEIN, G. W., GODET, J., ISSLER, J.-L., MARTIN, J.-C. ERHARD, P., LUCAS-RODRIGUEZ, R., PRATT, A. R. Status of Galileo frequency and signal design. In: ION GPS 2002: proceedings. 2002.

[22] ISSLER, J.-L., RIES, L., BOURGEADE, J.-M., LESTARQUIT, L., MACABIAU, C. Contribution of AltBOC to interference mitigation for civil aviation. In: 1st CNES Workshop on Galileo Signals: proceedings. 2006.

[23] IRSIGLER, M., HEIN, G. W., SCHMITZ-PEIFFER, A. Use of C-band frequencies for satellite navigation: benefits and drawbacks. GPS Solutions [online]. 2004. 8(3), p. 119-139. ISSN 1080-5370, eISSN 1521-1886. Available from: https://doi.org/10.1007/s10291-004-0098-2.

[24] BORRE, K. The Galileo signals with emphasis on LI OS. In: Power Electronics and Motion Control Conference: proceedings. 2006.

[25] PEDROS, R. C., O’DROMA, M. Galileo signal generation simulation analysis. Limerick: Department of Computer and Electronic Engineering. University of Limerick, 2009.

[26] SETLAK, L., KOWALIK, R. Examination of the unmanned aerial vehicle. ITM Web of Conferences [online]. 2019, 24, 01006. eISSN 2271-2097. Available from: https://doi.org/10.1051/itmconf/20192401006

[27] GAO, X. G., SPILKER, J., WALTER, T., ENGE, P., PRATT, A. R. Code generation scheme and property analysis of broadcast Galileo L1 and E6 signals. In: 19th International Technical Meeting of the Satellite Division ION GNSS 2006: proceedings, 2006.

[28] GAO, G., LORENZO, D., CHEN, D., LO, S., AKOS, D., WALTER, T., ENGE, P. Galileo GIOVE - a broadcast E5 codes and their application to acquisition and tracking. Stanford University. 2007, p. 1-11.

[29] HEIN, G. W., AVILA-RODRIGUEZ, J.-A., WALLNER, S., PRATT, A. R., OWEN, J., ISSLER, J., BETZ, J. W., HEGARTY, C. J., LENAHAN, S., RUSHANAN, J. J., KRAAY, A. L., STANSELL, T. A. MBOC: the new optimized spreading modulation recommended for Galileo L1 OS and GPS L1C. In: 2006 IEEE/ION Position, Location and Navigation Symposium: proceedings. 2006. ISBN 0-7803-9454-2. Available from: https://doi.org/10.1109/ PLANS.2006.1650688.

[30] SETLAK, L., KOWALIK, R. Analysis, mathematical model and selected simulation research of the GNSS navigation receiver correlator. MATEC Web of Conferences [online]. 2018, 210, p. 1-11. eISSN 2261-236X. Available from: https://doi.org/10.1051/matecconf/201821005008

[31] AVILA-RODRIGUEZ, J.-A., HEIN, G. W., WALLNER, S., ISSLER, J.-L., RIES, L., LESTARQUIT, L., DE LATOUR, A., GODET, J., BASTIDE, F., PRATT, T., OWEN, J. The MBOC modulation: the final touch to the Galileo frequency and signal plan. Navigation [online]. 2008, 55(1). ISSN 0028-1522. Available from: https://doi.org/10.1002/j.2161-4296.2008.tb00415.x.

[32] JULIEN, O., MACABIAU, C., ISSLER, J.-L., RIES, L. 1-bit processing of composite BOC (CBOC) signals. In: ESA-CNES Workshop on GNSS Signals: GNSS Signal 2007: proceedings. 2007.

[33] PRATT, A. R., OWEN, J. I. R. Performance of GPS Galileo receivers using m-PSK BOC signals. In: International Technical Meeting of the Institute of Navigation ION-GNSS 2003: proceedings. 2003.

[34] REBEYROL, E., MACABIAU, CH., LESTARQUIT, L., RIES, L., ISSLER, J.-L., BOUCHERET, M. L., BOUSQUET, M. BOC power spectrum densities. In: National Technical Meeting of the Institute of Navigation ION-NTM 2005: proceedings. 2005.

[35] SETLAK, L., KOWALIK, R. Examination of multi-pulse rectifiers of PES systems used on airplanes compliant with the concept of electrified aircraft. Applied Sciences [online]. 2019, 9(8), 1520. Available from: https://doi.org/10.3390/app9081520

[36] SOELLNER, M., ERHARD, P. Comparison of AWGN code tracking accuracy for alternative-BOC, complex-LOC and complex-BOC modulation options in Galileo E5-band. In: European Navigation Conference ENC-GNSS 2003: proceedings. 2003. 